\section{EL DEVENIR DEL CINE MUSICAL DE HOLLYWOOD}

\author{
Luisa Moreno Cardenal \\ Universidad de Valladolid \\ lumoca@hmca.uva.es
}

Cómo citar este artículo/Citation: Moreno Cardenal, L. (2015). “El devenir del cine musical de Hollywood". Arbor, 191 (774): a256. doi: http://dx.doi.org/10.3989/arbor.2015.774n4011

Recibido: 3 junio 2014. Aceptado: 3 octubre 2014

RESUMEN: Los géneros cinematográficos delimitados por la industria de Hollywood a lo largo de las primeras décadas del siglo $X X$ viven, cien años después, un proceso de revisión y metamorfosis que da como resultado el nacimiento de nuevos subgéneros y el desdibujamiento de otros que, durante décadas, tuvieron una entidad inequívoca e imprescindible para entender el cine como espectáculo y fenómeno de masas. Uno de esos géneros en periodo de extinción es el musical. Mostramos aquí un somero recorrido por el devenir del género desde su nacimiento hasta comienzos del siglo XXI, tratando de localizar las claves de su éxito y de su declive y fijándonos especialmente en algunos títulos importantes que cuentan, además de con maravillosas bandas sonoras, con números de baile escenificados para construir la dialéctica entre sus protagonistas.

PALABRAS CLAVE: Hollywood; Cine musical; comedia romántica; baile; pareja; cine clásico; cine postclásico.

\section{THE RISE AND FALL OF HOLLYWOOD MUSICAL CINEMA}

Copyright: (c) 2015 CSIC. Este es un artículo de acceso abierto distribuido bajo los términos de la licencia Creative Commons Attribution-Non Commercial (by-nc) Spain 3.0.

ABSTRACT: Film genres which were defined and developed by Hollywood during the early decades of the 20th century are no longer the same: a hundred years after they were first born, they are undergoing profound changes and a thorough revision. As a result, new sub-genres are emerging and others that were once essential to the identity of film as a mass phenomenon are becoming blurred. One such film genre on the verge of extinction is the musical. This paper briefly traces out the way musicals developed, from their beginnings through to the early years of the 21st century, enabling the keys to their success and their decline to be identified. Some major productions, with outstanding soundtracks or choreography building an interaction between the leading roles, will be especially examined.

KEYWORDS: Hollywood; cinema; musical; romantic comedy; dance; couple; classical cinema; post-classical cinema. 


\section{UNA PUERTA DE CRISTAL RESPLANDECIENTE}

El cine musical es uno de los géneros más asentados históricamente en Hollywood, por lo que no es de extrañar que se le considere, como afirma Munsó Cabús (1996), un género fundamental para entender la historia del cine. A esta afirmación se le podrían sumar otras de similar contundencia como las que recoge Dunne (2004) en la introducción de su obra sobre el cine musical americano, al valorar la necesidad de seguir ahondando sobre esta temática, siguiendo la estela de estudios de referencia como los de Feuer (1992), que no duda en considerar que el musical es Hollywood magnificado; Citron (1992), quien afirma que el musical es la forma más popular de entretenimiento del mundo, o Marshall y Stilwell (2000), que señalan al musical como uno de los géneros cinematográficos más populares, tanto para el público como para los estudiosos del cine, por el espectáculo que ofrece, por la música, y por un resultado previsiblemente agradable mezclado con multitud de detalles en su puesta en escena. Pero en definitiva, Dunne alude sobre todo a su propio entusiasmo como espectador de este tipo de cine para explicar esa necesidad de ahondar en el género musical, algo que nos hace empatizar de inmediato con el citado autor al disponernos a desarrollar este artículo.

Resulta curioso comprobar que el interés académico por analizar la fascinación que genera el musical hollywoodense haya ido creciendo, en los últimos años, de manera inversamente proporcional a la producción de este tipo de películas. El asunto que queremos tratar aquí es, sobre todo, el fenómeno de progresiva desaparición de un género que fue señero en Hollywood tras el nacimiento del cine sonoro $y$, en el transcurso del siglo XX, evolucionó hacia una producción anecdótica o ligada a públicos muy concretos: infancia y adolescencia.

Si indagamos en lo que se ha escrito sobre cine musical, encontramos, sobre todo, literatura de índole histórica, industrial o biográfica, así como numerosas obras de carácter mitificador y nostálgico. Benet (1996) señala otros aspectos sobre los que suelen versar los estudios del género musical: "sobre las estructuras del espectáculo relacionadas con la aparición de la música y/o la danza, y sobre la manera de elaboración de un relato sometido a unas motivaciones y una lógica causal". También cabe señalar el trabajo que viene realizando un grupo de estudiosos norteamericanos entre los que destaca Altman (1987), que profundiza en la trascendencia del género desde el punto de vista sociológico, folklórico y mitológico, adentrándose en el terreno de la estética y la erótica de la música y los bailes. Feuer (1992), una de las estudiosas del tema seguidora de Altman, repara en el hecho de que se trata de un género que tradicionalmente no ha sido intelectualizado, planteando que "se precisa de una llave que nos abra la puerta de cristal resplandeciente que los musicales colocan entre ellos y cualquier forma de análisis intelectual. Los musicales parecen resistirse a su estudio, podemos desproveerlos de todo su adorno y debajo nos seguirá quedando el verdadero adorno".

Para atravesar esa puerta resplandeciente de la que habla Feuer y poder abordar el estudio de este género de producción tan masiva, sobre todo durante las tres primeras décadas de cine sonoro, podemos focalizar la atención en una serie de películas que se engloban dentro del género musical de Hollywood desde 1927 y que por su éxito de público o calidad, resistente al paso del tiempo, nos sirvan para revisar el devenir del género y tratar de entender su deriva. Para localizar un buen número de títulos que sean representativos es útil consultar trabajos de recopilación como el de Munsó Cabús (1996) y el de Stanley Green (1999). En el libro de Green se reúnen trescientos diez títulos (cantidad más manejable que la compilación de Munsó Cabús, que supera los mil) seleccionados con los siguientes criterios: calidad de las canciones y de los bailes, talento de los intérpretes, datos de taquilla y grado de popularidad, entre otros. A estos criterios podríamos sumar otro: la existencia de bailes de pareja en la puesta en escena, pues este factor nos da pistas de cómo ha ido evolucionando la representación de la dialéctica sexual a lo largo del tiempo en este tipo de cine. Teniendo en cuenta estos criterios se puede trazar un recorrido riguroso que abarque ocho décadas, desde la llegada del sonido al cine hasta los albores del siglo XXI.

\section{NACIMIENTO Y ESPLENDOR DEL MÁS EVASIVO DE TODOS LOS GÉNEROS}

En su personal revisión de la historia del cine norteamericano, Scorsese ${ }^{1}$ y Wilson (2001) hacen la siguiente apreciación: "Paralelamente a las películas de gangsters apareció un género muy diferente: el musical. Es una coincidencia muy interesante. La dureza de la época, la depresión, dio vida al más evasivo de todos los géneros. En aquella época, si alguien mostraba tener ambición, o se convertía en gangster, o se convertía en artista de espectáculos (...). Broadway era una metáfora de un país desesperado y destrozado. Ya fueras director o corista, tu vida dependía del éxito del espectáculo". 
Así pues, el género que es calificado aquí como "el más evasivo de todos los géneros", se configuró durante los años de la Gran Depresión, años en que la música melódica, el jazz y las Big Bands gozaban de una gran popularidad en los Estados Unidos, y la radio vivía su edad de oro; hombres y mujeres familiarizados con las canciones de moda, bailaban juntos en salones y clubs compaginando esta forma de ocio con la asistencia al cine. Tanto en los teatros de variedades como en las pantallas cinematográficas, bailarines con particular destreza ${ }^{2}$ codificaban los movimientos del cuerpo en armonía con la música, poniendo en escena maneras de acceder a la dialéctica sexual ${ }^{3}$.

El cine de Hollywood, que con el asentamiento del cine sonoro fue poco a poco tomando el relevo en popularidad a los espectáculos en vivo de teatros y cabarets, dio de inmediato un lugar protagonista al espectáculo musical; cabe recordar aquí que la primera película comercializada con sonido sincronizado fue The Jazz Singer (El cantor de jazz, Alan Crosland, 1927), versión cinematográfica de un éxito de Broadway de 1925 que evocaba un género teatral muy popular en la Norteamérica del siglo XIX, el minstrel, interpretado por actores blancos con los rostros pintados de negro que cantaban canciones de origen negro. "La literatura decimonónica está repleta de anécdotas sobre los dueños que llaman a sus esclavos de talento a la "casa grande" para actuar ante sus invitados, y desde su inicio la ministralía etíope era una imitación consciente de las canciones, bailes y ocurrencias del negro, llevada a cabo por actores blancos con la cara teñida" (Southern, 2001).

Por tanto el cine sonoro quiso contar de inmediato con los profesionales más destacados de los escenarios de Broadway. Bailarines, coreógrafos, escenógrafos, diseñadores de vestuario, cantantes, músicos y letristas que cosechaban éxitos en los teatros neoyorkinos desde finales del siglo XIX, pusieron su arte al servicio del cine, donde encontraron un nuevo modo de expresión, al contar con distintas escalas de plano y encuadres espectaculares, como los ideados por el coreógrafo y director de teatro y cine Busby Berkeley. Viniendo de donde venían muchos de los profesionales que hicieron posible que el cine musical consiguiera asentarse rápidamente, cobra sentido que se configurara un subgénero musical conocido como backstage $e^{4}$. Así pues, el musical de Broadway es, en gran medida, el origen del género musical cinematográfico y el germen de parte de sus películas: las del subgénero backstage.

En la década de los años treinta, Hollywood era ya una industria cultural consolidada y, como industria, creaba productos consumibles por el mayor número de personas posible, no sólo integrando en sus películas elementos que ya gozaban de éxito, como temas de música popular -tanto el jazz como los ritmos sudamericanos fueron fundamentales en el cine musical durante las dos primeras décadas del sonoro- sino también ofreciendo a los espectadores modelos de ser, estar y actuar, encarnados en sus estrellas y en sus relatos. Conflictos humanos y crisis, en sus más diversas dimensiones - transgresión, indeterminación, inmadurez, inmovilidad, torpeza, miedo, angustia...-, encontraban en los relatos de esta primera etapa del cine sonoro vías para ser afrontados y conducidos a través del erotismo, la determinación, la evolución, el movimiento, la destreza, el valor y el entusiasmo. No había conformismo ni resignación en el cine de Hollywood de estos años, sino deseo en acción apuntando a un objetivo inmerso en la dimensión del amor y de la creatividad.

La música, la radio, los teatros, los cines y las salas de baile estaban íntimamente relacionados en la organización de los tiempos de ocio de la sociedad occidental de los años treinta. El público acostumbraba a ir a bailar después de ir al cine y allí, en la sala de baile, tras haber visto una película musical, a veces se recurría a lo aprehendido en la sala cinematográfica. La industria de Hollywood fomentaba la conexión entre ambos espacios de ocio; además de poner en escena maneras simbólicas de resolver los conflictos planteados en los relatos, en los musicales se popularizaban canciones y coreografías que trascendían la pantalla y continuaban en las salas de baile para su disfrute mimético por parte de hombres y mujeres, que pasaban así de ser meros espectadores a actuar, aspirando, con sus recursos particulares, a vivir una experiencia similar a la de las estrellas. Las películas musicales generaban un alto grado de identificación que conducía a la acción.

Un ejemplo paradigmático de la producción hollywoodense de musicales de esta primera etapa lo constituye la serie de películas protagonizadas por Fred Astaire y Ginger Rogers a lo largo de la década de los treinta, películas que gozaron de una gran popularidad. "Estas películas, en esencia, eran historias sobre cómo hacer valer la independencia, sobre hacerse adulto y llegar a ser un hombre o una mujer; una exploración de lo masculino y de lo femenino; de la sexualidad" (Kuhn, 2002). Esta observación de Annette Kuhn es pertinente para abordar las películas musicales de Hollywood como textos que configuran la subjetividad de los espectadores, pues, imbricados 
en la trama, los bailes proponen pautas para entrar en contacto con el cuerpo propio, en armonía con la música, y con el cuerpo deseado y temido por desconocido, del sexo contrario, estableciendo los pasos a dar dentro del juego del cortejo.

Los años treinta se consideran la primera edad de oro del cine musical. La brillante producción de musicales en esta década se aprecia al revisar maravillosas películas con canciones y bailes como 42nd Street (Calle 42, Lloyd Bacon, 1933), Gold Diggers of 1933 (Vampiresas 1933, Mervyn LeRoy, 1933), Flying Down to Río (Volando hacia Río de Janeiro, Thornton Freeland, 1933), The Gay Divorcee (La alegre divorciada, Mark Sandrich, 1934), Top Hat (Sombrero de copa, Mark Sandrich, 1935), Follow the Fleet (Sigamos la flota, Mark Sandrich, 1936), Shall We Dance (Ritmo loco, Mark Sandrich, 1937) y Carefree (Amanda, Mark Sandrich, 1938), todas ellas éxitos más que notables, no solo por la música de sus bandas sonoras, sino también por los números coreográficos que, integrados en sus tramas, se aprendían para luego reproducirlos en las salas de baile ${ }^{5}$.

A partir de 1941, tras la entrada de Estados Unidos en la Segunda Guerra Mundial, la industria de Hollywood decidió incrementar la edición de musicales y organizó rodajes en tecnicolor en Argentina, Brasil y Cuba, alejándose así de las zonas de conflicto internacional. Se realizaron los Ilamados Wartime Musicals, películas destinadas no sólo a entretener al público, sino también a cultivar y reafirmar el espíritu patriótico en la sociedad americana. En estos años destaca también la consagración de Judy Garland y la serie "Road to...", con Bing Crosby, Bob Hope y Dorothy Lamour, los musicales de la Fox con vivísimos colores y con Carmen Miranda, Esther Williams y su natación, y las películas de la Universal con Deanne Durbin (Driver, 2001). Pero sin duda en esta década lo más destacado fue el trabajo del equipo de los profesionales que se agruparon en torno al productor y letrista ${ }^{6}$ Arthur Freed, de la Metro Goldwyn Mayer: "Ninguna de las grandes compañías logró hacerle la menor sombra a la Metro Goldwyn Mayer en la era Freed: ni la Warner con Doris Day, ni la Fox con Betty Grable, ni la Columbia con Rita Hayworth y algún biopic, ni Samuel Goldwyn con Danny Kaye" (Munsó Cabús, 1996).

Del equipo de Arthur Freed formó parte Gene Kelly y también Vincente Minnelli, quien debutó con la película musical Cabin in the Sky (Una cabaña en el cielo, 1943) con Freed como productor; había comenzado su carrera como tal en 1939 junto a Mervin LeRoy produciendo The Wizard of Oz (El mago de Oz, Victor Fleming), para posteriormente ser el responsable abso- luto de la producción de algunos de los grandes éxitos de una joven Judy Garland: Babes in Arms, For Me and My Gal, Babes in Broadway, Girl Crazy y Meet Me in St.Louis, que fue dirigida por Minnelli en 1941. Sobre Meet Me in St.Louis, Scorsese y Wilson (2001) hacen las siguientes apreciaciones: "Los protagonistas eran los miembros de una familia de clase media. Ya no era necesario ser artista profesional. ¡Cualquiera podía cantar y bailar si le apetecía! Cantar y bailar se convirtió en algo tan natural como hablar o respirar. (...) Las melodías se compusieron para fortalecer el argumento y caracterizar a los protagonistas. Expresaban la decadencia y el esplendor de las emociones personales. En ocasiones aparecían teñidas con una ironía agridulce cuando la familia se enfrentaba a un futuro incierto en la gran ciudad. Prevalecían la dulzura y la inocencia, pero con la explosión de dolor e ira de una niña, aparecieron repentinamente sombras inesperadas en esta obra perteneciente a una época nostálgica; (...) A mediados de los 40 ocurrió algo interesante: aparecieron tendencias sombrías en los musicales, del mismo modo que había ocurrido con el western y con las películas de gangsters. Incluso los musicales más convencionales hacían referencia al malestar de la posguerra".

Estas observaciones cobran especial importancia y sentido si analizamos los musicales de los años inmediatamente posteriores a la Segunda Guerra Mundial. Por muy ligeras que parezcan las tramas de lo que seguirán siendo en esencia comedias románticas, en los números de baile, concretamente en los bailes de pareja, la naturalidad y aparente sencillez características de las coreografías del musical clásico de los años treinta, son progresivamente sustituidas por complejos juegos de artificio, tanto en la forma como en el sentido simbólico de los bailes.

\section{SEGUNDA EDAD DE ORO (Y ARTIFICIO)}

Aun sin haber dejado de producirse musicales masivamente durante los años de la segunda contienda internacional, es en la posguerra cuando vuelve a brillar el género. Uno de los grandes éxitos que inaugura esta nueva edad de oro es Anchors Aweigh (Levando Anclas, George Sidney, 1945), película en la que Gene Kelly y Frank Sinatra interpretan a dos marineros que están de permiso en Los Ángeles. Cuatro años después triunfa On the Town (Un día en Nueva York. Stanley Donen y Gene Kelly, 1949), una nueva trama protagonizada por marineros de permiso producida por Arthur Freed para la MGM. Les seguirán obras tan populares e imprescindibles del género como $A n$ American in Paris (Un americano en París, Vincente 
Minnelli, 1951), Singin' in the Rain (Cantando bajo la Iluvia, Stanley Donen y Gene Kelly, 1952), Gentlemen Prefer Blondes (Los caballeros las prefieren rubias, Howard Hawks, 1953), The Band Wagon (Melodías de Broadway 1955, Vincente Minnelli, 1953), Kiss me Kate (Bésame, Kate, George Sidney, 1953), Brigadoon (Vincente Minnelli, 1954), Seven Brides for Seven Brothers (Siete novias para siete hermanos, Stanley Donen, 1954), Oklahoma (Fred Zinnemann, 1955), Guys and Dolls (Ellos y ellas, Joseph Leo Mankiewicz, 1955), The King and I (El Rey y yo, Walter Lang, 1956), Funny Face (Una cara con ángel, Stanley Donen, 1957) y Gigi (Vincente Minnelli, 1958).

Driver (2001) afirma que en los años cincuenta los musicales de la Metro Goldwyn Mayer "comenzaron a perder su chispa", acusando cómo, tras haber realizado trabajos originales en las décadas anteriores, los estudios prácticamente se limitaron a adaptar al cine éxitos musicales de Broadway, como Brigadoon, Oklahoma o Kiss me Kate. Otros autores dicen, por el contrario, que el apogeo del musical se alcanzó precisamente a principios de los años cincuenta: "MGM era por aquel entonces un lugar mágico en donde el productor Arthur Freed realizó clásicos tales como Un americano en París, Cantando bajo la Iluvia, Siempre hace buen tiempo, y Melodías de Broadway, 1955" (Munsó Cabús, 1996). Se podría decir también que esta década fue la era del musical Minnelli, con un estilo particular en el que inciden Scorsese y Wilson (2001): "Los musicales de Minnelli celebran el triunfo de lo imaginario sobre lo real. Cualquier aspecto de la realidad, por trivial que fuera, se podía transformar, estilizar e incorporar en un ballet: el mundo era un escenario y pertenecía a los que sabían cantar y bailar".

En paralelo a este mundo imaginario de Minnelli se realizan otras películas de género musical enmarcadas entre el backstage y el melodrama; el calificativo genérico de comedia romántica se va despegando poco a poco de los musicales de Hollywood: "Ha nacido una estrella (Cukor, 1954), llevó al género más lejos. Nos presenta a Judy Garland como una cantante mala que se convierte en estrella de cine mientras que James Mason, su mentor, sabotea su propia carrera. (...) El espectáculo debe continuar es el primer mandamiento del artista, pero Norman Maine se vio atrapado en el cruel laberinto del fingimiento, sin poder soportarlo más. Ni siquiera podía soportar verse a sí mismo. Romper los espejos fue su primer paso hacia la autodestrucción. Ya no era una comedia musical, era un drama musical sobre las tristes ironías del negocio del espectáculo" (Scorsese y Wilson, 2001).
La década de los cincuenta fue algo menos productiva que las anteriores, aunque de ella salieron, como hemos visto, algunas de las obras maestras del género y se asistió a la aparición de estrellas como Howard Keel, Debbie Reynolds, Mario Lanza, Leslie Caron, Elvis Presley, Mitzi Gaynor, Shirley Jones, Jane Russell y Marilyn Monroe además de un grupo de notables y jóvenes bailarines, entre ellos Bob Fosse, quien se convertirá en uno de los cineastas más emblemáticos de los años setenta.

Pero quizá lo más transcendental que ocurrió en los años cincuenta y que es imprescindible tener en cuenta para analizar el género que nos ocupa, es que apareció un nuevo tipo de música, el rock and roll. Esto dio lugar al éxito en las pantallas de uno de sus máximos representantes: Elvis Presley. Aunque la mayor parte de sus películas se estrenaron en los sesenta, las cuatro que lo hicieron en los cincuenta (Love Me Tender, Loving You, Jailhouse Rock y King Creole) fueron suficientes para sentar al mítico cantante en el trono de la nueva revolución socio-musical.

Hacia finales de los años cincuenta, con la desintegración de la unidad Freed-MGM, la tendencia realista que iba adueñándose de los estudios de Hollywood, cada vez más interesados en la problemática social, así como de la ascensión casi imparable del rock and roll con todo lo que entrañaba de cambio de ideas y costumbres, hizo que el musical tradicional empezase a perder entidad y poder de convocatoria.

\section{EL DESDIBUJAMIENTO DE UN GÉNERO MÍTICO}

En la década de los sesenta comienza a manifestarse el declive del género musical, aunque se produjeron algunas películas que conforman una parte importante de la historia del cine y de la cultura popular, como West Side Story (Robert Wise y Jerome Robbins, 1961), My Fair Lady (George Cukor, 1963), Mary Poppins (Robert Stevenson, 1964) y The Sound of Music (Robert Wise, 1965).

Como ya hemos mencionado, Elvis Presley fue la gran estrella de esta década en los musicales de Hollywood; llegó a intervenir en veintiséis películas para teenagers editadas por distintas compañías con gran éxito de público. En general, los sesenta se caracterizaron por los cambios de criterios de los estudios de Hollywood, condicionados en gran medida por el triunfo del rock and roll, que tanto gustaba a la media de los espectadores habituales del cine, los jóvenes, pero también por cierta inclinación por parte de los cineastas hacia un crudo realismo que empezaba a dibu- 
jar las líneas estilísticas y temáticas de lo que acabaría siendo el género más popular y extendido de la creación cinematográfica contemporánea, el thriller, capaz de impregnar a todos los géneros hollywoodenses que se habían gestado en los comienzos de la industria.

En este sentido cabe destacar, dentro de esta crítica década para el género musical, la película que Sydney Pollack dirigió en 1969 sobre el fenómeno de los maratones de baile habituales en los años treinta y sobre los que Driver hace estas apreciaciones: "La Depresión tuvo una influencia poco afortunada en el baile: se creó el maratón de la danza, una prueba de resistencia en la que participaban las parejas con un único objetivo: ganar dinero (...) Existía un total contraste entre el sueño de Hollywood y la dura realidad de la Depresión económica que se dejaba sentir en los salones de baile estadounidenses: si los personajes de Astaire y Rogers bailaban por amor, miles de hombres y mujeres en EEUU bailaban por dinero.(...) Récord: un maratón que duró 24 semanas y 5 días y al que las autoridades locales pusieron fin. Había espectadores, patrocinadores, el acontecimiento se seguía como un culebrón y tenía una clara naturaleza de explotación: el coste era escaso y el sufrimiento inmenso, llegando a costar la vida incluso en algún caso. En 1933 llegaron a ser oficialmente ilegales" (Driver, 2001). La película de Pollack, They Shoot Horses, Don't They? (Danzad, danzad, malditos) es un drama realista, no catalogado habitualmente como musical en los estudios del género, pero donde el baile de pareja, al ritmo de las músicas que suenan en el infernal escenario donde se desarrolla el concurso, juega un papel determinante poniéndose en escena su deconstrucción.

En los años setenta destaca la realización de películas con carácter documental centradas en estrellas del momento: Janis Jopplin, Joe Cocker, Jimi Hendrix, The Beatles, Alice Cooper y Richie Havens entre otros. La explicación que los historiadores dan a este fenómeno es que buena parte de los cineastas pertenecían a la misma generación del público para el que trabajaban, los jóvenes, y esto hizo que el musical pop se pusiese de moda. La década comienza con el documental Woodstock (Michael Wadleigh, 1970), cuya estela siguieron varias producciones posteriores: Celebration at Big Sur, Fillmore, Nashville, Soul to Soul y Concert for Bangladesh entre otros títulos. Contagiadas del mismo espíritu destacan algunas producciones de estilo hippy como Jesus Christ Superstar (Norman Jewison, 1973) y Hair (Milos Forman, 1979), más versiones cinematográficas de exitosos espectáculos de Broadway.
El número de películas musicales que gozan de cierto éxito de público en los años setenta se reduce considerablemente respecto a décadas anteriores, aunque fueron varias las que alcanzaron gran éxito: Fiddler on the Roof (Norman Jewison, 1971), Cabaret (Bob Fosse, 1972), New York, New York (Martin Scorsese, 1977), Saturday Night Fever (John Badham, 1977), Grease (Randal Kleiser, 1978) y All That Jazz (Bob Fosse, 1979) son algunas de ellas.

En los ochenta reina el musical pop destinado al público juvenil, destacando especialmente títulos como Fama (Alan Parker, 1980) y Flashdance (Adrian Lyne, 1983), con coreografías de grupo y bailes individuales enmarcados en el terreno del mundo profesional de la danza y que desataron cierta pasión por la danza moderna entre los jóvenes de la época. Dirty Dancing (Emile Ardolino, 1987) quizá sea el título más popular de esta década, y el más conocido hoy en día, gracias, sobre todo, a las numerosas reposiciones por televisión que ha tenido. Feuer (1992) dice que esta película supone, aún recurriendo a los códigos narrativos de su época, un intento de rescatar como género firme al cine musical. Con la perspectiva histórica que aportan las casi tres décadas pasadas desde entonces, podríamos afirmar que este intento fue fallido.

Cabe mencionar, además, otros títulos de mayor o menor calado popular de la década de los ochenta como Xanadu (Robert Greenwald, 1980), The Blues Brothers (Granujas a todo ritmo, John Landis, 1980), Pennies From Heaven (Dinero caído del cielo, Hervert Rosse, 1981), A Chorus Line (Richard Attenborough, 1985), One from the Heart (Corazonada, 1982) y Cotton Club (1984), estos dos últimos dirigidos por Francis Ford Coppola, quien ya hizo una incursión en el género musical en 1968 con Finian's Rainbow sin alcanzar el éxito esperado, a pesar de tener un reparto encabezado por el maestro del género Fred Astaire. Musicales como Yentl (Barbra Streisand, 1983) o Victor Victoria (Blake Edwards, 1982), al servicio de sendas divas de la canción -Barbra Streisand el primero, Julie Andrews el segundo- abordan, entre números musicales, la temática de la identidad sexual.

En los años noventa destacan en especial algunas producciones de animación de Disney, que vienen a engrosar la lista de títulos que desde finales de los años treinta del pasado siglo, tras el estreno de Snow White and the Seven Dwarfs (Blancanieves $y$ los siete enanitos, David Hand, 1937), unen dibujos animados y música. Tras el éxito obtenido a finales 
de los ochenta por The Little Mermaid ${ }^{7}$ (La Sirenita, 1989), hay una avalancha de películas musicales de animación sobre las que es interesante señalar cómo crean un pequeño corpus de relatos en los que perviven las tramas simbólicas del cuento maravilloso y donde la dialéctica sexual es abordada de manera notoria, también con bailes de pareja. Ese corpus estaría integrado fundamentalmente por Beauty and the Beast (La Bella y la Bestia, 1991), Aladdin (Aladino, 1992), Pocahontas (1992), The Hunchback of Notre Dame (El Jorobado de Notre Dame, 1996), y Anastasia (1997).

Otros films musicales producidos en Hollywood que se estrenan en la década de los noventa son el biopic sobre Eva Perón, Evita (Alan Parker, 1996)- esta vez con la diva de la canción Madonna como protagonista-, y Everyone Says I Love You (Todos dicen I Love You, Woody Allen, 1996). En la secuencia final de esta película, el hombre y la mujer protagonistas, que están divorciados, rememoran melancólicamente los buenos tiempos de su relación. En el desarrollo de la conversación que mantienen a orillas del Sena, un escenario que figura aquí como cliché romántico ${ }^{8}$, la mujer comienza a cantar una melodía significativa para la pareja, la conocida canción I'm Through Whit Love, para después bailarla juntos. Vemos entonces cómo, de manera inesperada en el desarrollo del baile, la mujer, impulsada levemente por el hombre, se desplaza por el aire. Aquello que se presenta como un momento emocionante, deriva entonces en un artificioso esperpento. Quizá se pudiese interpretar como una manera imaginativa de poner en escena la sublimación del amor que aún se profesan los que antes fueron matrimonio, pero, atendiendo a la desconcertante sensación que causa la irrupción de esos sobrenaturales desplazamientos aéreos de la mujer, mientras el hombre la observa, se evidencia la falta de credibilidad del cineasta hacia lo que está tratando de poner en escena: una oportunidad de reconstruir simbólicamente la relación de pareja a través de la música y el baile. Este número musical sería un ejemplo de evolución hacia la parodia que en cierta forma caracterizaría el devenir del género musical, como apunta Viñuela (2012) en su estudio de ciertas películas musicales contemporáneas realizadas en Italia.

Tras siete décadas de cine musical y una continua adaptación técnica, estética y argumental a los tiempos, a partir del cambio de siglo, los finales felices que caracterizaban a los musicales de las primeras décadas de cine sonoro, ahora sólo parecen recurrentes en las tramas destinadas al público infantil (cine de animación) y adolescente, este último ya no tanto seguidor del género como de algunas estrellas de la música popular que pudiesen aparecer en escena: Chayanne y Vanessa Williams formando pareja de baile en Dance with Me (Baila Conmigo. Randa Haine, 1998), o Zac Efron y Vanessa Hudgens, protagonizando la saga de películas High School Musical: tres entregas estrenadas respectivamente en los años 2006, 2007 y 2008 en Disney Channel. Esta saga es incluida por Cohan (2010) en su recopilación de títulos con los que defiende la teoría de la reaparición del género musical en el siglo XXI. Sin duda es curioso que en la primera década del nuevo milenio, no solo hubiese una serie de películas musicales notables de las que hablaremos en breve, sino también una apreciable producción de musicales para adolescentes, pues a la saga de High School Musical se le suma la de Step Up, con cinco entregas hasta la fecha que recorren desde el estreno de la primera en 2006 hasta la más reciente de 2014. Con la voluntad de creer en ese renacimiento del género musical que defiende Cohan, podríamos señalar un parecido entre estas sagas y la serie de películas protagonizadas por Fred Astaire y Ginger Rogers en los años treinta: el hecho de que la dialéctica sexual entre los protagonistas se articule a través de canciones y de bailes; cantando y bailando se pueden superar las barreras entre el hombre y la mujer protagonistas: él un deportista y ella una intelectual en la saga High School Musical; él un chico de la calle y ella una disciplinada bailarina en la saga Step Up. Pero más allá de recurrir a la fórmula incombustible de cómo librar la "batalla de los sexos", presente en general en toda comedia romántica, hay otros aspectos fundamentales que tienen que ver con la calidad de las producciones cinematográficas que hacen incomparable la trascendencia estética de "la saga" Astaire-Rogers -cuyas películas son consideradas hoy en día como auténticas joyas y clásicos de la historia del cine-, con la de las sagas con las que en el nuevo siglo se quiere deleitar a los adolescentes románticos. El tiempo dirá si serán también clásicos.

En cualquier caso, el tipo de películas producidas en el siglo XXI revisadas hasta ahora no ha sido el único cine musical que hemos podido ver en los últimos tiempos. Ha habido otra serie de títulos dispersos, dispares, pero interesantes, que repasamos en el último tramo de nuestro recorrido, donde además recopilamos ideas sobre el género musical más reciente y sobre qué se vislumbra en el horizonte. 
CONCLUSIONES: SOMBRAS DEL MUSICAL DE HOLLYWOOD Y BRILLOS DEL OTRO LADO DEL PLANETA

El primer film musical que alcanzó popularidad en el siglo XXI fue el drama de aire romántico decimonónico Moulin Rouge! (Baz Luhrmann, 2001). Inspirado en la famosísima ópera de Verdi La Traviata, narra una historia de estética bohemia donde acaba triunfando el amor, aunque de una manera trágica. Dentro del subgénero backstage, esta película pone en escena de manera abigarrada y espectacular varios números musicales que componen un collage de canciones populares de las últimas décadas del siglo $\mathrm{XX}$, contando así con la complicidad de cierta generación de espectadores que van reconociendo los temas versionados a lo largo del metraje. Ya los primeros musicales cinematográficos compusieron sus bandas sonoras con temas que Broadway y el Tin Pan Alley habían popularizado previamente. En su estudio sobre las grandes canciones de la edad de oro del musical americano, Sánchez (2005) reseña que el Tin Pan Alley (Callejón de la Sartén de Hojalata) era el sobrenombre con el que se conocía a la calle 28 de Nueva York desde finales del siglo XIX, y que se cree que este nombre estaba inspirado en el ruido de los pianos aporreados en el interior de las numerosas editoriales que había en esa calle, donde pianistas y promotores de canciones (song-pluggers) tocaban las composiciones de la editorial a petición de los clientes, con el objetivo de vender partituras para espectáculos locales, orquestas de baile y sobre todo a particulares, ya que a principios del siglo XX la principal forma de disfrutar de la música en el hogar era tocando el piano. Así pues, el cine musical de las primeras décadas del sonoro (años treinta, cuarenta y cincuenta) es a menudo una cita continua a temas conocidos, buscando empatizar con el público al mostrarle algo que va a reconocer. Por tanto, la eficaz fórmula musical a la que recurre Luhrmann en Moulin Rouge! no es novedosa, sino que procede del musical clásico y se rescata en el musical postclásico. En su estudio del cine musical español, y aludiendo a títulos como El otro lado de la cama (Emilio MartínezLázaro, 2002), afirma Fraile (2010): "el uso de canciones pop reinterpretadas, adaptadas, orquestadas, se ha convertido en una práctica habitual y marca de fábrica del musical contemporáneo".

Es también un fenómeno propio del cine de los tiempos actuales, en todos los géneros, los remakes - la imitación estética de algunos clásicos del cine, para contar, así mismo, con la complicidad del espectador que se siente interpelado al reconocer un relato o un estilo. Viñuela (2012), en su estudio del cine de
Roberta Torre, señala que en su película musical de tintes amateurs Tano da morire (1997) existe una clara intertextualidad con el conocido musical hollywoodense West Side Story (Robert Wise, 1961) en algunas escenas, y en otras con la no menos conocida película Saturday Night Fever (Fiebre del sábado noche. John Badham, 1977). En el Hollywood actual encontramos casos concretos de remakes de películas musicales como la nueva versión que se hizo de Hairspray (John Waters, 1988), dirigida por Adam Sankman en 2007, y con la participación de uno de los mitos del cine musical de los setenta, John Travolta, haciendo el papel femenino que en la película de Waters hizo el actor fetiche de este, Divine. Así pues, el remake adopta un aire kitsch propio de la postmodernidad.

Otro tipo de sombras detectadas en el cine musical del siglo XXI son las procedentes de un estilo de realización o de dirección. En Chicago (Rob Marshall, 2003) hay resonancias estéticas del cine de Bob Fosse, y tiene lógica pues fue él quien dirigió esta obra para los escenarios de Broadway en el año 1975, siendo también coautor y coreógrafo. Así pues, la impronta Fosse está presente en la obra de Marshall. Chicago es un musical puramente postclásico, donde el tono del thriller (género prototípico de las últimas décadas, como ya anotábamos anteriormente) es el predominante, y la temática nada tiene que ver con el romanticismo ni con la comedia. Tampoco gozaron de esos ingredientes otros musicales previos a Chicago con el sello directo de Bob Fosse: ni Sweet Charity (1969), ni Cabaret (1972), ni All That Jazz (1979). Seis años después de Chicago, Rob Marshall dirigió Nine (2009), adaptación al género musical de la película Otto $e$ mezzo (Fellini, ocho y medio. Federico Fellini, 1963). Nuevamente encontramos aquí el estilo de Fosse, director que se había inspirado también en esa famosa película de Fellini para componer la premonitoria All That Jazz: ocho años después de su estreno, Fosse morirá del mismo modo que lo hace el coreógrafo protagonista de este relato con tintes autobiográficos.

La manera de conectar al género musical con el público adulto habitual de producciones de Hollywood se ha encontrado en los últimos años con películas como Shall We Dance? (¿Bailamos? Peter Chelsom, 2004) donde Richard Gere tuvo ocasión de mostrar sus destrezas con el baile de salón junto a Jennifer López en una película de temática terapéutica con el baile de pareja como solución, siendo este film una adaptación de un éxito previo del cine japonés titulado Dansu Wo Shimasho Ka? (Masayuki Suo, 1994); y también con Les Misérables (Tom Hooper, 2012), una 
coproducción entre Estados Unidos y Reino Unido en la que se adaptó a la pantalla uno de los grandes éxitos del teatro musical desde que compusiese sus canciones Claude-Michel Schönberg, basándose en la obra literaria que Victor Hugo escribió en 1862. Tras su estreno en el Palais des Sports de París en 1980, Les Misérables ha recorrido los escenarios teatrales de las grandes ciudades, cosechando un éxito imparable que se intensificó con la versión cinematográfica. Así, la incombustible fórmula de la adaptación al cine de un musical teatral engrosa los formatos que adopta el género musical contemporáneo, en su discreta presencia entre las producciones de Hollywood más actuales.

A través de los escasos títulos musicales reseñables producidos en la meca del cine en los últimos tiempos, hemos señalado una serie de categorías que podrían considerarse como alternativas creativas o estrategias comerciales para sacar partido en el siglo XXI a este género antológico: versiones cinematográficas de obras teatrales, remakes, estilizaciones que rememoran a los grandes directores, parodias, festivales juveniles y cuentos maravillosos podrían ser algunas de esas categorías que hacen sobrevivir al género. El estreno de Moulin Rouge! en 2001 o de Chicago en 2003, pudieron hacernos pensar que el musical cinematográfico quizá estaba resurgiendo en el lugar donde nació, pero ese resurgimiento no alcanza la fuerza necesaria para afirmar que este tipo de películas conforman hoy en día un género especial con suficiente cuerpo. No obstante, algunos de los interesados en este género ya estamos acomodándonos en un oasis hallado lejos del semidesierto occidental de películas musicales que es hoy Hollywood. Ese Oasis está al otro lado del globo terráqueo y se llama Bollywood. Como señala Grant (2012), el único país, más allá de los Estados Unidos, que tiene una importante tradición de cine musical es India ${ }^{9}$, donde un noventa por ciento de las películas comerciales incorporan números musicales. Canciones y bailes son parte habitual de la puesta en escena del cine hecho en Bollywood, independientemente de que estemos ante relatos románticos o tramas criminales, y en sus escenas musicales se mezclan ritmos tradicionales de India con ritmos americanos, tanto jazzísticos del norte como caribeños del sur. No hay que ignorar que esta interculturalidad también se ve reflejada en ciertas producciones de Hollywood en las que aparece algún número musical que se impregna del estilo de Bollywood; sin ir más lejos el titulado Hindi Sad Diamonds, de Moulin Rouge!, o la escena con la que finaliza Mirror, Mirror, la versión del relato clásico Blancanieves que dirigió en 2012 Tarsem Singh, un director indio, para más señas, que decidió poner como colofón del cuento de hadas el único número musical de la película, en el que todos los personajes cantan y bailan la canción / Believe in Love al estilo de Bollywood.

También señala Grant lo importante que es en la cultura popular india las canciones de las películas. Las bandas sonoras suelen salir a la venta y promocionarse antes de los estrenos cinematográficos, y los espectadores acuden en masa a las salas de proyección ya familiarizados con unas melodías que suelen estar interpretadas siempre por los mismos cantantes. Estos cantantes componen un grupo de estrellas paralelo a las de la pantalla, quienes hacen playback de las canciones mientras despliegan en escena sus dotes extraordinarias para el baile. Así pues en Bollywood ocurre, pero de una forma especialmente intensa, lo que pasaba antes en Hollywood: que la industria musical y la cinematográfica en gran medida iban de la mano: "si hay una forma anterior de la cultura popular que ha sido una influencia significativa en la conformación del cine musical, es la industria de la música popular, de la que las propias películas musicales son una parte" (Grant, 2012).

Para finalizar nuestro recorrido por este género tan fascinante, solo añadir otra observación que podría servir para tratar de entender la caída en picado desde lo más alto que ha sufrido el cine musical en Occidente. La deconstrucción del musical clásico tiene su traducción en la mezcla de géneros y tonos, rompiendo con la fórmula de la comedia romántica a la que respondían los musicales de la edad de oro. Así, aparte del punto de inflexión que supuso la irrupción de los nuevos tipos de música pop a partir de los años cincuenta, con el rock and roll a la cabeza, y que quebraron, inevitablemente, la escenificación musical del romance, al separar físicamente a los hombres y a las mujeres en los bailes, el musical de Hollywood de principios del siglo XXI converge con las corrientes desmitificadoras de Occidente, donde la progresiva desritualización de las relaciones sexuales se manifiesta también, inevitablemente, en el campo de la representación cinematográfica, que durante décadas construyó simbólicos escenarios de deseo que el público quería recrear cantando, bailando y enamorándose de la misma forma que lo hacían los protagonistas de las películas que veían en la pantalla. 


\section{NOTAS}

[1] Martin Scorsese, coautor del libro Un recorrido personal por el cine norteamericano, es sobre todo conocido por su extraordinario trabajo como director de cine, pero son también reseñables sus interesantes aportaciones reflexivas, no solo sobre el mundo del cine americano, en el que trabaja desde los años sesenta, sino también sobre otros tipos de cine, como el italiano, cuyo visionado durante la infancia identifica como el origen de su pasión por este arte, tal y como explica de manera excepcional en el documental Il mio viaggio in Italia (1999).

[2] El término destreza lo utilizamos aquí en el sentido platónico (techne). Platón agrupa las bellas artes con el concepto genérico de destreza; danza y canto figuran clasificadas como artes con intervención musical. (Beardsley y Hospers, 1997).

\section{BIBLIOGRAFÍA}

Altman, R. (1987). The American Film Musical. Bloomington: Indiana University Press.

Beardsley, M. C. y Hospers, J. (1997). Estética. Historia y fundamentos. Madrid: Cátedra.

Benet, V. J. (1996). Ámame esta noche y la estabilización narrativa en el musical, Secuencias, 5, pp.47-68.

Citron, S. (1992). The Musical From the Inside Out. Chicago: Elephant Paperback.

Cohan, S. (ed.) (2010). The Sound of Musicals. London, New York: Palgrave MacMillan.

Driver, I. (2001). Un siglo de baile. Barcelona: Blume.

Dunne, M. (2004). American Film Musical Themes and Forms. Jefferson: McFarland.
[3] Este sería un matiz de corte sociológico y folklórico, en el terreno de la estética y la erótica de la música y los bailes, que conectaría con el enfoque de estudios como los que llevan a cabo Altman y Feuer sobre el género, y a los que aludíamos en la introducción.

[4] Películas musicales cuya trama gira en torno a la preparación de un espectáculo.

[5] Las producciones de la RKO repitieron esta fórmula a lo largo de la serie protagonizada por Astaire y Rogers con buenos resultados, lanzando nuevos bailes populares como The Carioca (Flying down to Río, Freeland, 1933), The Continental (The Gay Divorcee, Sandrich, 1934), The Piccolino (Top Hat, Sandrich, 1935) o The Yam (Carefree, Sandrich, 1938).

Feuer, J. (1992). El musical de Hollywood. Madrid: Verdoux, S.L.

Fraile P. (2010). Música de cine en España: señas de identidad en la banda sonora contemporánea. Badajoz: Diputación de Badajoz.

Grant, B. K. (2012). The Hollywood Film Musical. New Jersey: Wiley-Blackwell.

Green, S. (1999). Hollywood Musicals Year by Year. Milwaukee: Hal Leonard Corporation.

Kuhn, A. (2002). An Everyday Magic. Cinema and Cultural Memory. London, New York: I.B. Publishers.

Marshall, B. y Stilwell, R. (2000). Musicals: Hollywood and Beyond. Wilmington: Intellect Books.
[6] Arthur Freed fue autor, entre otras canciones, de la famosísima Singin' in the Rain, que se publicó en 1929 con música de Nacio Herb Brown.

[7] The Little Mermaid ganó en el año 1989 sendos Oscars a la mejor banda sonora y a la mejor canción.

[8] El estatus de cliché romántico no solo se remite aquí al tópico de París, ciudad del amor, sino también a la intertextualidad patente que se establece con el primer número de baile de pareja de An American in Paris (Un americano en París, Vincente Minnelli, 1951), donde vemos a Gene Kelly y Leslie Caron en una escena nocturna a orillas del Sena acortando distancias a través de una coreografía.

[9] Además, hay que recordar que India es el país con mayor producción cinematográfica del mundo.

Munsó Cabús, J. (1996). El cine musical (volumen I. Hollywood 1927-1944). Barcelona: Royal Books S.L.

Sánchez, L. (2005). Lunas de papel y polvo de estrellas. Compositores y letristas en la edad de oro del musical. Lleida: Milenio.

Scorsese, M. y Wilson, M. H. (2001). Un recorrido personal por el cine norteamericano. Madrid: Akal.

Southern, E. (2001). Historia de la música negra norteamericana. Madrid: Akal.

Viñuela, E. (2012). El cine musical de Roberta Torre: un retrato postmoderno de la Sicilia de finales del siglo XX. Arbor, 187, 758. doi: 10.3989/arbor.2012.758n6007 